\title{
Consultoria para a Diversão: Como gerenciar o mercado de entretenimento?
}

Consulting for fun: How to manage the entertainment market?

Recebido em 30.12.2012. Aprovado em 02.10. 2013 Avaliado pelo sistema double blind review

\author{
Christian Tirelli \\ christian.tirelli@gmail.com \\ Universidad de Castilla-La Mancha - Toledo -Espanha
}

Sabrina de Lima e Silva Garcia

sabs.garcia@gmail.com

Universidade Federal Fluminense (UFF) e Escola Superior de Propaganda e Marketing (ESPM) - Rio de Janeiro - RJ - Brasil

\section{Elisa do Nascimento Fonseca \\ elizanfonseca@gmail.com}

Escola Superior de Propaganda e Marketing (ESPM) - Rio de Janeiro - RJ - Brasil

\section{Resumo}

Com o crescimento acelerado do consumo de serviços de entretenimento no Brasil, torna-se necessário entender de que forma as empresas que atuam neste mercado estão se preparando para gerir adequadamente seus negócios. Neste contexto, o presente artigo teve como objetivo investigar as necessidades estratégicas de tais empresas, a fim de avaliar a implantação de uma consultoria especializada em entretenimento. Por meio de uma análise prévia de dados secundários, identificou-se que não há uma empresa no Brasil que esteja focada neste negócio. Para comprovar tais dados, foi realizada uma pesquisa qualitativa com especialistas de diversas áreas do entretenimento, que geraram informações relevantes para a etapa quantitativa da pesquisa, também realizada com funcionários de empresas do setor do entretenimento. Os resultados das pesquisas permitem concluir que há oportunidade para que uma consultoria em entretenimento atue no Brasil, principalmente nas cidades de São Paulo e Rio de Janeiro, onde o setor cresce com maior velocidade. Além disso, foi possível identificar que as principais atividades de consultoria desejadas pelos clientes são pesquisas de marketing, treinamento e desenvolvimento de pessoas e desenhos de projetos para busca de patrocinadores.

Palavras-chave: consultoria, entretenimento, gestão.

\section{Abstract}

With the rapid growth in consumption of entertainment services in Brazil, it is necessary to understand how the companies operating in this market are arranging themselves to properly manage their business. In this context, the present study aimed to investigate the strategic needs of such companies in order to evaluate the implementation of a consulting company specialized in entertainment. Through a preliminary analysis of secondary data, it was identified that there isn't a company in Brazil that is focused in this business. To confirm these data, a qualitative research with experts from different fields of entertainment was conducted, which generated information relevant to the quantitative stage of the research, also conducted with employees of companies in the entertainment industry. Research results indicate that there is opportunity for a consultancy in entertainment acts in Brazil, mainly in the cities of São Paulo and Rio de Janeiro, where the sector grows faster. Moreover, it was identified that the main consulting activities desired by customers are marketing research and training and development of people and business plan to search for sponsors.

Keywords: consultance, entertainment, management. 


\section{Introdução}

Segundo pesquisa da PriceWaterHouseCoopers (2011), a indústria do entretenimento é uma das que mais cresce no Brasil. Pensando nesta indústria, é importante salientar que o conceito de entretenimento está diretamente relacionado a uma ideia de divertimento, de realização de uma atividade prazerosa que provoca bem estar e ocupa o tempo ocioso.

A palavra tem origem latina, vem de inter (entre) e tenere (ter) incorporando a ideia de "ter entre". Gabler (2003, p.32, apud TRIGO, 2003) diz que a evolução da palavra entertainment significa "aquilo que diverte com distração/recreação" e "espetáculo público ou mostra destinada a interessar e divertir". O ser humano procura preencher o seu tempo ocioso com atividades que possuam o poder de proporcioná-lo sensações de prazer, diversão e recreação.

Diante das transformações sofridas pela sociedade e do avanço tecnológico, as relações entre trabalho e lazer foram se modificando, resultando na valorização do lazer que ocasionou o crescimento do mercado de entretenimento.

De acordo com Limeira (2008, p. 35) "o antigo princípio de que o trabalho dignifica, e que faz dele o centro da vida, vem perdendo a importância. Em seu lugar, a busca pelo prazer individual e a convivência familiar e social parecem ganhar cada vez mais espaço na vida cotidiana". Trigo (2003, p.11) enfatiza a presença do entretenimento no dia a dia da sociedade, uma vez que perpassa tribos, classes sociais, gerações, faixas etárias e que está presente inclusive nos campos onde a seriedade é fundamental, como o da educação.

O conjunto das atividades que chamamos de entretenimento faz parte do chamado consumo de experiências que busca estimular as sensações de seu público por meio dos cinco sentidos, despertando alguns sentimentos que podem estar associados à memória do consumidor. Todo produto é constituído de atributos, sejam eles tangíveis ou intangíveis, fornecendo ao cliente a solução para seus problemas (KOTLER, 2011). No caso do entretenimento, o produto é um estímulo constituído por atributos experimentais, ou seja, aqueles que causam sensações prazerosas ou de bem estar durante o consumo. Tais sensações correspondem a uma quarta atividade econômica, na qual o consumidor paga para dedicar seu tempo a eventos, como um show de música (PINE e GILMORE, 1999).

0 produto do entretenimento possui algumas características bem particulares, como o ciclo de vida curto, conteúdo baseado na criatividade e adequação a tendências e mudanças de estilos. Pode-se considerar 0 entretenimento como uma atividade que consegue atingir toda sociedade, sua segmentação é feita por meio dos preços cobrados e pela carga cultural de cada atividade (TRIGO, 2003). Com a chegada do sistema capitalista, 0 entretenimento começou a se enquadrar no modelo de consumo atual, deixando para trás a imagem de atividade descomprometida e marginal. Antes visto como um produto considerado supérfluo, o entretenimento vem demonstrando sua importância e representatividade, portando-se como segmento produtivo, capaz de gerar empregos e riquezas (BERTINI, 2008).

Mesmo sendo um setor que vem se mostrando cada vez mais lucrativo, o entretenimento ainda não é um tema muito estudado academicamente. Há dificuldade para encontrar pesquisas e dados coletados de maneira suficiente para estudar este assunto (KRYKHTINE,F; LOBATO.F; MENDES.I, 2006).

Além de ser um setor relevante para a economia, composto por organizações esportivas, culturais, de mídia, de turismo, entre outras, o entretenimento é um dos responsáveis pela promoção das manifestações culturais de um país. Por meio dele, podem ser conhecidas algumas peculiaridades culturais de cada população (NETO, 2005) 


\section{Consultoria para a Diversão: Como gerenciar o mercado de entretenimento?}

A importância econômica do entretenimento e a grande demanda por esse tipo de atividade esbarra na falta de empresas especializadas que possam auxiliar na gestão desta indústria, principalmente no ramo de consultorias. Além disso, é importante entender como o entretenimento tem sido gerido pelas empresas que atuam neste mercado. Todas estas questões foram ponderadas ao longo deste estudo, por meio de análise de dados e pesquisas realizadas com profissionais da área. Serão apresentadas as atuais formas de gestão das empresas que atuam no mercado de entretenimento, quais serviços vêm sendo oferecidos e quais áreas ainda não estão sendo atendidas com eficiência. Por fim, o trabalho apresenta um diagnóstico de mercado favorável à implementação de uma empresa de consultoria especializada em entretenimento.

\section{Referencial Teórico}

\section{O Mercado de Entretenimento}

Os Estados Unidos ocupam o primeiro lugar no que diz respeito à produção, comercialização e lucros no setor de entretenimento. Um dos grandes fatores que contribuíram para alcançar essa posição privilegiada foi 0 pioneirismo. No século XIX, o americano Phineas Taylor Barnum, mais conhecido como P.T Barnum, foi um dos primeiros a exercer profissionalmente a arte do entretenimento. Barnum fazia sucesso mostrando ao povo curiosidades como objetos, animais ou pessoas estranhas que ia coletando ao longo de suas viagens. Alguns deles ficaram famosos, como a Sereia de Fiji, que na verdade era um torso de macaco costurado num rabo de peixe. Ele foi o criador do chamado "circo moderno", criado em 1867 sob uma tenda com um show itinerante chamado "O Maior Espetáculo da Terra", que sobrevive até hoje no "Ringling Bros. and Barnum \& Bailey Circus" (Siqueira, 2004).

O setor de entretenimento vem se mostrando cada vez mais rentável, segundo a pesquisa Global Entertainment and Media Outlook: 2011-2015, lançada pela PricewaterhouseCoopers (2011), os gastos globais no setor em 2010 registraram aumento de $4,6 \%$ e o Brasil vem se destacando, juntamente com a China, como potenciais consumidores de entretenimento. Estima-se que, juntos, os dois países tenham ao crescimento anual médio de $11,4 \%$ até 2015. As especulações são favoráveis à continuidade desse crescimento. Segundo a PricewaterhouseCoopers (2011), o mercado brasileiro está, em 2012, na décima colocação no ranking mundial de consumo de entretenimento, tendo expectativa de chegar à sétima posição em 2015, com o consumo médio de US $\$ 56,7$ bilhões anuais.

O mercado de entretenimento no Brasil se divide em diversos segmentos e muitos deles não possuem um mercado estruturado e organizado.Certas empresas dominam alguns setores, outras se destacam e outras têm sua área de atuação bastante reduzida tendo em vista a forte concorrência de empresas estrangeiras. A empresa referência deste mercado é a TV Globo, que faz parte das Organizações Globo e foi fundada pelo empresário Roberto Marinho em 1965. Atualmente, a emissora é a maior da América Latina e a quarta maior do mundo, assistida por 80 milhões de pessoas diariamente, sendo, assim, uma grande formadora de opinião. A TV Globo especializou-se em fazer telenovelas, que são vendidas atualmente para mais de trinta países. Como qualquer canal de TV aberta no Brasil, a TV Globo teve sua concessão aprovada pelo governo e é líder de audiência desde então. Sua missão está atrelada ao conteúdo nacional e mais de $90 \%$ de sua grade exibe programas realizados pela própria emissora. Em 1998, criou a Globo Filmes, para estender sua participação também no mercado de cinema. A Globo Filmes co-produziu desde então, dez das dez maiores bilheterias de filmes nacionais no Brasil. Além de TV e cinema, as Organizações Globo também atuam em diversos segmentos. Relacionados ao mercado de entretenimento, temos a Rádio Globo, a Globosat e o jornal O Globo. 
O mercado de cinema, além da Globo Filmes, conta com a participação de muitas produtoras independentes que lançam, em média, de dois a três filmes por ano. No entanto, ao falar em distribuição desses filmes, temos a participação de poucas empresas, conta-se com as majors americanas (Sony, Warner, Paramount, Universal, Disney, Fox, etc), que participam nesse mercado justamente pela facilidade de investimento levando em conta os incentivos fiscais criados pelo governo brasileiro. Na exibição, temos a liderança do Grupo UCI uma empresa do grupo Cinemark e também algumas empresas brasileiras como a Severiano Ribeiro e o Grupo Estação. Em relação à música e ao mercado de shows musicais, percebe-se uma concentração de empresas não brasileiras atuando no mercado como a Mondo Entretenimento e a Time For Fun.

Com o desenvolvimento das tecnologias, os meios de comunicação se tornaram cada vez mais eficazes, 0 maior desafio das empresas que trabalham no ramo do entretenimento atualmente é acompanhar 0 desenvolvimento tecnológico desses meios. Além de ser uma ferramenta de marketing muito importante, os meios de comunicação são essenciais para o produto final da maioria das empresas nesse setor de atuação. Uma pesquisa realizada em diversos países, inclusive no Brasil, chamada "O Futuro da Mídia" foi desenvolvida pela empresa de consultoria Deloitte e pelo Harrison Group (2009) teve o objetivo de estudar os hábitos de consumo de mídia dos brasileiros e identificar os desafios e as oportunidades das empresas na comunicação. Segundo a Deloitte (2009), "as empresas que mais rapidamente perceberem os recentes movimentos de consumo de mídia são as que, provavelmente, terão mais chances de êxito comercial". Desde a "revolução digital", o celular deixou de ser apenas um telefone e se transformou num aparelho com inúmeras funções. A distribuição de músicas via celular já faz parte de um dos grandes negócios das empresas de telefonia e é um expressivo canal de distribuição de música. Além disso, as empresas de telecomunicações estão cada vez mais estendendo seus negócios para o mercado de entretenimento, como a Oi fez ao lançar a Oi FM, a Oi Internet e a Oi TV e a Claro, ao também lançar a Claro TV.

Outro setor que está ampliando seus negócios tendo em vista as mudanças da era digital é o das empresas de distribuição de música. Um exemplo desse movimento é vivenciado pela empresa inglesa Virgin, que decidiu expandir o seu negócio nas mais diversas áreas, o que levou à atual diversidade do negócio. Atualmente, a empresa atua em outros diversos setores do mercado de comunicações e entretenimento com a Virgin Phone, Virgin TV, Virgin Broadband, Virgin Móbile e Virgin Radio (com diversos canais digitais), pertencentes à Virgin Media Television.

Vislumbrando a inovação conceitual de eventos de entretenimento, podemos citar o Cirque Du Soleil. Para Marco D'Amico (2010), vice-presidente sênior de marketing do grupo, "a primeira chave para a abertura do nosso sucesso foi sempre estabelecer e manter um equilíbrio entre arte e comércio. É extremamente difícil ter essa balança hoje em dia. E pouquíssimas empresas conseguem, especialmente aquelas que lidam com sentimento e entretenimento ao vivo", afirmou ele.

Avaliando o ambiente no qual o mercado de entretenimento está envolvido, pode-se dizer que há uma maior regulação governamental junto ao setor audiovisual, por meio da agência reguladora (ANCINE) e das leis Rouanet, Audiovisual, Funcines, premiações, etc. A Lei Rouanet também pode ser utilizada em outros setores como a música, o teatro e a dança, permitindo que empresas invistam por meio de mecenato ou patrocínio com até $100 \%$ de isenção fiscal (Ministério da Cultura, 2012). O setor do audiovisual mostrou-se totalmente dependente da regulação do Estado e da existência das leis de incentivo fiscal, chegando a quase zero a produção no final dos anos 80 e início dos 90, quando a Lei Sarney foi revogada com o Plano Collor. Tendo em vista o tamanho do investimento, o setor do audiovisual, enquanto não se sustentar como indústria, com base em propostas mais estratégicas das leis de fomento e atuação mais mercadológica dos envolvidos, ainda dependerá de políticas legais que Ihe assegurem crescimento. Outra lei importante de atuação em um dos setores com maior crescimento no Brasil é a Lei de Incentivo ao Esporte, que permite que patrocínios e doações para a realização de projetos desportivos sejam descontados do imposto de renda. A lei prevê que a pessoa jurídica pode deduzir até $1 \%$ (um por cento) do imposto devido, já a pessoa física pode chegar a $6 \%$ (seis por 


\section{Consultoria para a Diversão: Como gerenciar o mercado de entretenimento?}

cento) de dedução do imposto devido na Declaração de Ajuste Anual (Lei n 11.438, de 29 de Dezembro de 2006).

\section{O Mercado de Shows Musicais}

O mercado fonográfico passou por uma transformação importante após as inovações tecnológicas ocorridas no início do século XXI, gerando uma crise na indústria da música. Entretanto, de acordo com Anna Carolina Braile (2010), ao se falar em crise da indústria da música, esta refere-se ao modelo aplicado pela indústria do CD. Com 0 advento da internet e novas tecnologias, houve uma mudança na forma de se consumir música (ANDERSON, 2007).

Segundo Herschmann e Albornoz (2009), o mercado de música tradicional é sustentado por dois pilares: "a comercialização massiva de obras gravadas em diferentes suportes físicos reproduzíveis em distintos equipamentos e os direitos econômicos que incidem sobre o uso público dos fonogramas". No entanto, esse modelo vem sendo modificado devido a três principais fatores: "a) $O$ aumento da distribuição on-line: através de redes (telecomunicações, internet) e programas de informática ( $\mathrm{P}^{2} \mathrm{P}^{1}$ ) que se servem destas. b) As mudanças nas tecnologias: entre as quais cabe assinalar as redes digitais com uma maior banda larga." (HERSCHMANN; ALBORNOZ, 2009) "c) O aperfeiçoamento dos dispositivos terminais móveis: telefones celulares e dispositivos portáteis digitais variados (MP3, MP4, etc.) e bastante populares hoje." (CALVI, 2007 apud HERSCHMANN; ALBORNOZ, 2009).

Todas essas mudanças causadas pelo avanço da tecnologia digital alteraram o mercado das gravadoras, mas demonstram ser uma oportunidade para o mercado de shows. Além de aparecerem novos modelos de distribuição e produção muito mais acessíveis, fazendo com que artistas de públicos menores tenham a oportunidade de ganhar espaço nesse mercado, os shows e as apresentações têm crescido para contrabalancear os prejuízos nas vendas de CDs.

O Brasil possui um mercado de música nacional consistente e diversificado, com os rankings das músicas mais tocadas no país formados por estilos diferentes como o sertanejo, pagode, rock e MPB, deixando a cargo do produtor de shows saber explorar o portfólio que tem nas mãos à medida que conhece o seu cliente final. Este mercado cresce mesmo que no Brasil haja barreira dos altos preços, pelo país ser um dos maiores mercados consumidores de shows no mundo, e a competição entre as produtoras brasileiras andar bastante acirrada $(0$ GLOBO, 2012) especialmente no que se refere a shows internacionais. O fato do Rio de Janeiro, que ostenta 0 título ser a segunda cidade mais cara das Américas (segundo a consultoria britânica ECA International, 2012) e a $13^{a}$ do mundo (de acordo com pesquisa feita pela consultoria Mercer, 2011), corrobora tal afirmação.. Mesmo com valores altos, Pedro Seiler, um dos fundadores do sistema de crowd fundig2 "Queremos", diz que "o Brasil é hoje um dos maiores mercados consumidores de shows no mundo." (CULTURA E MERCADO, 2012)

Em relação ao mercado de shows musicais, percebe-se que os principais fornecedores são as Casas de Espetáculo, cujo poder de barganha é mais alto, pois não existem muitos lugares nas cidades brasileiras para a realização de shows. Isso poderá ser melhorado após as obras de infraestrutura na cidade para a Copa do Mundo de 2014 e para as Olimpíadas de 2016, com o surgimento de novos locais para receberem os artistas internacionais e nacionais.

Os clientes desse mercado costumam ser fiéis às bandas e artistas e não à empresa produtora. A empresa deve se preocupar, portanto, em trazer os melhores artistas e proporcionar a melhor estrutura para manter um bom portfólio. O poder de barganha do cliente, portanto, é maior. Em caso onde isso não ocorre, justifica-se que a 
empresa produtora soube trabalhar bem sua marca atraindo o público interessado em viver uma experiência de qualidade e intensa, onde nem sempre a banda é o principal atrativo (a marca "Rock n Rio", por exemplo). Nesse caso o poder de barganha do cliente diminui.

Algumas empresas produtoras e promotoras de shows possuem parcerias ou são donas de casas de shows como a Time For Fun, que é proprietária do Credicard Hall, Citibank Hall RJ e Citibank Hall SP. Outras fecham acordos com patrocinadores, como a Dream Factory e a roda gigante da Skol, por exemplo. A rivalidade entre os concorrentes é alta e há uma briga acirrada pelas verbas dos grandes patrocinadores, que tendem a investir na empresa com melhor infraestrutura e que oferece o melhor portfólio de shows realizados.

Os novos entrantes são as gravadoras. Essas entram no segmento de shows por meio de empresas-irmãs, ou seja, pertencentes ao mesmo dono. As gravadoras passaram a empresariar artistas, investindo em apresentações ao vivo, em busca de mais rendimentos. Não existem produtos substitutos para esse mercado. 0 DVD musical e a TV são produtos que retroalimentam essa indústria.

As informações apresentadas permitem que se faça a análise das forças competitivas, propostas por Porter (1979), esse instrumento é utilizado em análises de mercado, visando obter informações essenciais no planejamento estratégico de lançamentos de novos produtos ou serviços, reposicionamento de mercado e estudo de atratividade dos setores. $\mathrm{Na}$ análise de Porter serão pesquisados os novos entrantes no mercado, a ameaça dos produtos substitutos, o poder de barganha dos fornecedores e a rivalidade existente na indústria (Tabela 1).

Tabela 1: Quadro de análise das forças de Porter - Shows Musicais

\begin{tabular}{|c|c|c|c|c|}
\hline NOVOS ENTRANTES & 4 & 3 & 2 & 1 \\
\hline Conhecimento técnico & $X$ & & & \\
\hline Diferenciação de serviços & $x$ & & & \\
\hline Necessidade de investimentos & $x$ & & & \\
\hline Vantagens desvinculadas da escala & & $x$ & & \\
\hline AMEAÇAS DE SUBSTITUTOS & 4 & 3 & 2 & 1 \\
\hline Preço e qualidade dos subsitutos & $X$ & & & \\
\hline Propensão dos clientes em substituir & & & & $X$ \\
\hline Custo de troca & & $X$ & & \\
\hline PODER DE BARGANHA DOS FORNECEDORES & 4 & 3 & 2 & 1 \\
\hline Concentração de fornecedores & & & $X$ & \\
\hline Importância de seus produtos para os compradores & & & $X$ & \\
\hline Custo de mudança para os clientes & & $x$ & & \\
\hline Disponibilidade de produtos substitutos & & & $X$ & \\
\hline Diferenciação de produtos/serviços & & & $x$ & \\
\hline PODER DE BARGANHA DOS CLIENTES & 4 & 3 & 2 & 1 \\
\hline Diversidade dos clientes & & $X$ & & \\
\hline
\end{tabular}




\section{Consultoria para a Diversão: Como gerenciar o mercado de entretenimento?}

\begin{tabular}{|c|c|c|c|c|}
\hline Grau de informação sobre o mercado/produto adquirido & & & & $x$ \\
\hline Disponibilidade de produtos/serviços substitutos & $x$ & & & \\
\hline RIVALIDADE NA INDÚSTRIA & 4 & 3 & 2 & 1 \\
\hline Crescimento rápido da indústria & & & & $\mathrm{X}$ \\
\hline Ausência de diferenciação entre os produtos & & & & $x$ \\
\hline Barreiras de saída & & $x$ & & \\
\hline Diversidade entre os concorrentes & $x$ & & & \\
\hline Altos custos fixos/armazenagem & & $x$ & & \\
\hline
\end{tabular}

A Tabela 2 mostra a inferência se o mercado demonstra maior tendência a ameaças ou a oportunidades.

Tabela 2: Quadro de avaliação geral das forças de Porter - Shows Musicais

\begin{tabular}{|c|c|c|c|c|}
\hline \multicolumn{5}{|c|}{ AVALIAÇÃO GERAL DAS CINCO FORÇAS } \\
\hline Força & $\begin{array}{c}\text { Pontos } \\
\text { Atribuídos }\end{array}$ & $\begin{array}{c}\text { Predominância } \\
\text { de Ameaça }\end{array}$ & $\begin{array}{l}\text { Predominância } \\
\text { de Oportunidade }\end{array}$ & A 0 \\
\hline Novos Entrantes & 15 & Acima de 8 & Até 8 & $\mathrm{X}$ \\
\hline Substitutos & 8 & Acima de 6 & Até 6 & $x$ \\
\hline Fornecedores & 11 & Acima de 10 & Até 10 & $x$ \\
\hline Clientes & 8 & Acima de 6 & Até 6 & $x$ \\
\hline Mercado & 12 & Acima de 10 & Até 10 & $x$ \\
\hline Total Geral & 54 & Acima de 40 & Até 40 & $X$ \\
\hline
\end{tabular}

Com base nesta análise é possível identificar uma ameaça ao negócio, principalmente em relação a novos entrantes. Isso vai de encontro ao fato de haver um crescente número de novas empresas atuantes no mercado de shows musicais. Essa questão também pode justificar o aumento do poder de barganha dos fornecedores, que acabam ameaçando também as empresas que atuam neste setor. É importante estar atento a este cenário ao oferecer serviços a essas empresas, pois já existe um custo de mudança representativo e que pode impactar a venda de novos serviços a elas.

\section{O Mercado de Eventos Esportivos}

O esporte passou por sua modernização durante a Revolução Industrial e pelo idealismo clássico de Pierre de Coubertin, do fim do século XVIII e meados do século XIX, tornando-se altamente rentável e profissionalizado, sobretudo a partir da segunda metade do século XX. Ao assumir seu contexto de "moderno", o esporte incorpora conceitos que dizem respeito não somente ao próprio esporte, mas sim à sociedade moderna, com questões como rendimento, profissionalismo, especialização, metodização, lucratividade e busca de recordes. Com isso, o esporte começou a deixar de lado seu caráter lúdico e assumiu uma forma de atividade comercial, tanto para 
os praticantes quanto para os dirigentes e todos aqueles ligados de alguma maneira prática esportiva. (CANAN, 2006).

Os eventos esportivos aparecem a partir de 2012 como uma ótima opção de investimentos em entretenimento no Brasil,com o aumento do incentivo fiscal e com a iminência de grandes eventos acontecendo no país, é importante estar atento a esse setor. Segundo o levantamento divulgado pela Pluri Consultoria (2012), a proximidade de eventos como a Copa do Mundo de 2014 e os Jogos Olímpicos de 2016 impulsionou 0 crescimento do PIB do esporte brasileiro em cerca de 20\%. Mesmo com esse significante crescimento, o PIB do esporte corresponde a apenas 1,6\% do PIB total do Brasil, cerca de 67 bilhões de reais. Estima-se que esse percentual chegue aos 1,9\% após os Jogos Olímpicos do Rio de Janeiro de 2016. Com a chegada dos grandes eventos esportivos garante-se investimento para os próximos anos, principalmente no futebol, que representa uma parcela de $53 \%$ no PIB do esporte. Um exemplo de retorno de investimento neste setor foram os jogos Pan Americanos realizados no Rio de Janeiro em 2007, que fortaleceu a candidatura do Brasil a sediar as Olimpíadas. Isso porque foram gastos aproximadamente $\mathrm{R} \$ 3,7$ bilhões em infraestrutura, que ficou de legado para candidatura do Brasil à sede de outros eventos esportivos. (PLURI, 2012).

Além dos investimentos em infra-estrutura, os eventos esportivos de grande porte trazem os patrocínios de grandes empresas e os direitos de transmissão em TV e Internet. Segundo Marin (2008) "altas somas de dinheiro são envolvidas para adquirir os direitos de transmissão dos jogos". Um exemplo é a transmissão do Campeonato Brasileiro, transmitido pela Rede Globo e que corresponde ao patrocínio mais caro do país. A televisão enquadra-se também como possível produto substituto dos eventos esportivos, pois os espectadores podem optar pelo conforto da sua casa ou ir até estabelecimentos comerciais em vez de prestigiarem as competições em seus locais de origem. Porém, de acordo com a pesquisa Dossiê Esporte (2005), realizada pelo Instituto Ipsos Marplan para o canal SporTV, os eventos esportivos possuem um público com alto grau de fidelidade que valoriza a ida ao evento, muitas vezes levando toda a família.

Atua como fornecedores no mercado de eventos esportivos um grande número de empresas de alimentação, infra-estrutura, confecções, mídia e material esportivo. Tais fornecedores possuem um poder de barganha baixo, devido ao grande número de concorrentes envolvidos. Já as produtoras e os profissionais de esportes tem 0 poder de barganha mais elevado, devido ao número reduzido de opções disponíveis no mercado, tornando-se, portanto, um ponto crítico para este setor. A demanda desses fornecedores vem principalmente do Governo, Patrocinadores, Confederações, Federações, Ligas e Associações.

Observa-se que com a profissionalização do esporte, algumas empresas surgiram no mercado atuando no gerenciamento de carreiras de atletas profissionais, na promoção de eventos esportivos, na implantação de atividades esportivas dentro de organizações e no marketing esportivo. A grande maioria dessas novas empresas se posiciona como "consultoria esportiva", atuando em um nicho específico do mercado.

As informações apresentadas permitem que se faça a análise das forças competitivas, também do mercado de eventos esportivos (Tabela 3). 


\section{Consultoria para a Diversão: Como gerenciar o mercado de entretenimento?}

Tabela 3: Quadro de análise das forças de Porter - Eventos Esportivos

\begin{tabular}{|c|c|c|c|c|}
\hline NOVOS ENTRANTES & 4 & 3 & 2 & 1 \\
\hline Conhecimento técnico & $X$ & & & \\
\hline Diferenciação de serviços & $x$ & & & \\
\hline Necessidade de investimentos & $x$ & & & \\
\hline Vantagens desvinculadas da escala & & $x$ & & \\
\hline AMEAÇAS DE SUBSTITUTOS & 4 & 3 & 2 & 1 \\
\hline Preço e qualidade dos substitutos & $\mathrm{X}$ & & & \\
\hline Propensão dos clientes em substituir & & & & $x$ \\
\hline Custo de troca & & $x$ & & \\
\hline PODER DE BARGANHA DOS FORNECEDORES & 4 & 3 & 2 & 1 \\
\hline Concentração de fornecedores & & & & $\mathrm{X}$ \\
\hline Importância de seus produtos para os compradores & & & $x$ & \\
\hline Custo de mudança para os clientes & & $x$ & & \\
\hline Disponibilidade de produtos substitutos & & $x$ & & \\
\hline Diferenciação de produtos/serviços & & & $x$ & \\
\hline PODER DE BARGANHA DOS CLIENTES & 4 & 3 & 2 & 1 \\
\hline Diversidade dos clientes & & & & $\mathrm{X}$ \\
\hline Grau de informação sobre o mercado/produto adquirido & & & & $x$ \\
\hline Disponibilidade de produtos/serviços substitutos & $x$ & & & \\
\hline RIVALIDADE NA INDUSTRIA & 4 & 3 & 2 & 1 \\
\hline Crescimento rápido da industria & & & & $\mathrm{X}$ \\
\hline Ausência de diferenciação entre os produtos & & & & $x$ \\
\hline Barreiras de saída & & $x$ & & \\
\hline Diversidade entre os concorrentes & $x$ & & & \\
\hline Altos custos fixos/armazenagem & & & & $x$ \\
\hline
\end{tabular}

$\mathrm{Na}$ análise das forças de Porter no setor de eventos esportivos há uma tendência maior de ameaças do que de oportunidades. Isso pode ser explicado pelo maior profissionalismo deste setor. Já existem empresas com experiência que beneficiam quem já está neste setor, mas ao mesmo tempo abre brecha pra que novas empresas atuem devido à boa receptividade de mercado. Para vender serviços a esse tipo de empresa, é necessário estar atento principalmente a esses novos entrantes, pois eles podem modificar os modelos de negócio existentes, exigindo uma mudança também na atuação de possíveis fornecedores. A Tabela 4 mostra como esta avaliação foi feita. 
Tabela 4: Quadro da avaliação geral das forças de Porter - Eventos Esportivos

\begin{tabular}{|c|c|c|c|c|}
\hline \multicolumn{5}{|c|}{ AVALIAÇÃO GERAL DAS CINCO FORÇAS } \\
\hline Força & $\begin{array}{c}\text { Pontos } \\
\text { Atribuídos }\end{array}$ & $\begin{array}{l}\text { Predominância } \\
\text { de Ameaça }\end{array}$ & $\begin{array}{l}\text { Predominância } \\
\text { de Oportunidade }\end{array}$ & A 0 \\
\hline Novos Entrantes & 15 & Acima de 8 & Até 8 & $\mathrm{X}$ \\
\hline Substitutos & 8 & Acima de 6 & Até 6 & $x$ \\
\hline Fornecedores & 11 & Acima de 10 & Até 10 & $x$ \\
\hline Clientes & 6 & Acima de 6 & Até 6 & $x$ \\
\hline Mercado & 10 & Acima de 10 & Até 10 & $x$ \\
\hline Total Geral & 50 & Acima de 40 & Até 40 & $\mathrm{X}$ \\
\hline
\end{tabular}

\section{Método}

Com objetivo de entender, avaliar e mensurar as oportunidades de mercado existentes para uma consultoria especializada em entretenimento foi realizada uma pesquisa de marketing, dividida em duas etapas, uma exploratória e outra descritiva.

Após o levantamento dos dados secundários, que atuam como apoio para o desenvolvimento da pesquisa, foi constatado que, para que se possa trabalhar o problema de pesquisa "oportunidades de negócio em entretenimento", era necessário abranger diversos aspectos deste tema. Verificando a amplitude do tema trabalhado, tornou-se necessária a realização de uma etapa qualitativa na pesquisa, que possibilitasse tanto uma melhor compreensão do tema e definição das fronteiras da pesquisa, quanto o levantamento de variáveis a serem utilizadas na construção do instrumento de coleta de dados (MALHOTRA, 2001), que vem a ser a etapa quantitativa do trabalho, tratada posteriormente.

Foi realizado um grupo focal, no dia 27 de abril de 2009, na sala 9E da Escola Superior de Propaganda e Marketing (ESPM) no Rio de Janeiro, onde um moderador treinado, utilizando-se de um roteiro de questões abertas previamente desenvolvido guia a discussão de aspectos do tema da pesquisa por um grupo. Para 0 grupo focal foram convidados especialistas de diversos setores do entretenimento, procurando abranger o que foi pesquisado na etapa de dados secundários. Os principais objetivos da técnica do grupo focal foram: avaliar conceitos e atributos de novos produtos ou negócios; gerar hipóteses sobre opiniões, costumes, crenças, valores, experiências, atitudes e estilo de vida; gerar informação para estruturar um questionário de pesquisa e ajudar a interpretar informações oriundas de uma pesquisa quantitativa (MALHOTRA, 2001). Os participantes do grupo focal atuam profissionalmente nas seguintes áreas: turismo, cinema, eventos esportivos, carnaval, agência de publicidade, casas de espetáculo e parque temático. Após a transcrição, foi feita a análise do debate do grupo focal, por meio do quais foram levantas algumas variáveis importantes para a construção do questionário da etapa quantitativa.

Pela análise da etapa exploratória foram trazidos os seguintes pontos: as empresas estão cada vez mais seletivas quando se trata de investimentos em entretenimento; os eventos corporativos estão sendo utilizados como forma de conversarem com seus clientes; está havendo uma maior pulverização dos eventos; a geração de conteúdo está se tornando diferencial no mercado de entretenimento; o mercado de entretenimento ainda é amador, principalmente no Rio de Janeiro; o preço dos ingressos e a violência são grandes vilões do 


\section{Consultoria para a Diversão: Como gerenciar o mercado de entretenimento?}

entretenimento no Rio de Janeiro; não existem modelos de negócio formais e definidos neste mercado; 0 investimento em esportes tem caído nos últimos anos; o Carnaval deixou de ser algo cultural e tem se tornado um comércio; falta infraestrutura e ajuda do governo pra organizar o entretenimento no Rio de Janeiro; não há pessoas capacitadas e especialistas que atuem no entretenimento; o grande diferencial do Rio de Janeiro foi a mistura do morro com o asfalto e isso não é desenvolvido; é necessário maior investimento em pesquisas; a cultura está sendo usada como ferramenta de marketing, mas nem sempre da melhor forma; é preciso saber falar com quem tem a idéia do evento e com quem tem dinheiro para investir, sabendo transitar por estes dois mundos; o Rio de Janeiro tem um enorme potencial, mas está tudo "largado", sem cuidado especial; é necessária uma empresa parceira que saiba gerenciar o negócio.

Com base na etapa exploratória da pesquisa, partiu-se para a etapa de concepção da pesquisa descritiva. Para tal, utilizou-se o método de survey, que se baseia no interrogatório dos sujeitos da pesquisa a fim de descobrir a percepção, a motivação e o comportamento dos mesmos acerca do tema apresentado. As principais vantagens deste método, segundo Malhotra (2001), dizem respeito à facilidade de sua aplicação e à confiabilidade dos dados, bem como ao fato de a codificação, análise e interpretação dos dados ser relativamente simples. 0 principal objetivo da survey foi confirmar as principais informações trazidas na etapa exploratória, por meio de um método mais formal, que permitiu medir numericamente as hipóteses levantadas no problema da pesquisa.

O instrumento de coleta utilizado foi o questionário. Para a sua realização, um survey pode ser diferenciado em quatro categorias quanto ao método de sua aplicação: método telefônico, método postal, método eletrônico e método pessoal. 0 método eletrônico foi 0 utilizado pela presente pesquisa, sendo que os sujeitos foram entrevistados virtualmente, por meio do recebimento de um link em seu e-mail que dava acesso à pesquisa na Internet. Foram utilizados no questionário dois tipos de perguntas estruturadas: perguntas de múltipla escolha e perguntas escalonadas. As perguntas de múltipla escolha oferecem aos entrevistados um elenco de respostas e, dentre estas, ele deve optar por uma ou duas. Importante salientar que as alternativas deveriam conter todas as respostas possíveis. Para isso, utilizou-se o recurso de incluir uma alternativa intitulada de "Outras". Além disso, as alternativas devem ser mutuamente excludentes. Estas alternativas das questões de múltipla escolha foram elaboradas com base nos resultados do grupo focal, e foram selecionadas para tentar minimizar a tendenciosidade da entrevista.

O entrevistado tem a tendência a marcar a primeira ou a última questão de uma lista. Para evitar tal comportamento, diversas formas de perguntas foram elaboradas, e misturadas entre si, visando não condicionar o entrevistado a um raciocínio mecânico. Nas perguntas escalonadas foi utilizada uma escala do tipo Lickert. Ela exige que o entrevistado indique um grau de concordância ou discordância com cada uma das afirmações sobre objetos de estímulo. A escala utilizada tem cinco categorias que compreendem as seguintes alternativas: discordo totalmente, discordo em parte, não concordo nem discordo, concordo em parte e concordo totalmente. Após ter sido elaborada a primeira versão do questionário, foram feitas revisões que o tornaram instrumento considerado pronto para ser pré-testado. 0 pré-teste do questionário consistiu em verificar como ele se comporta em uma situação real de coleta de dados. Através de sua aplicação com dois entrevistados, foram observados os seguintes aspectos do questionário: compreensão das questões, reações do entrevistado, tempo de aplicação, compreensão das escalas e sequencia das questões. O pré-teste revelou necessidade de ajuste na ordem das questões, vocabulário e novas opções de resposta, assim como a eliminação de algumas perguntas e uma nova formulação de outras. Desta forma, obteve-se a versão final do instrumento de coleta de dados primários.

A população da pesquisa é composta de funcionários (independente do cargo) de empresas que atuam direta ou indiretamente com o mercado do entretenimento. Definida a técnica de pesquisa, foi necessário avaliar qual tipo de amostra seria utilizada. Segundo Kotler (1998), as amostragens não probabilísticas, apesar de não

CGE * v. 1 * n. 1 * Jan-Abr $2013 * 46-63$ 
possibilitar a mensuração de erros, são muito úteis em pesquisa de marketing. Para esta pesquisa foram escolhidos os sujeitos da pesquisa através da técnica snowball sampling (ou amostragem "bola de neve"), onde representantes de empregas ligadas ao entretenimento receberam um e-mail com link para responder a pesquisa. Após a resposta, eles encaminharam esse e-mail para pessoas conhecidas do mercado, que por sua vez encaminhavam a outras pessoas.

As entrevistas foram realizadas com pessoas das cidades do Rio de Janeiro e São Paulo, virtualmente (com auxílio do site de pesquisa Survey Monkey), durante os meses de maio e junho de 2009. A análise do conteúdo das entrevistas foi baseada na teoria exposta na fase anterior do artigo.

A seguir, serão apresentados e analisados os resultados obtidos na pesquisa quantitativa, separados de acordo com o questionário enviado aos respondentes.

\section{Análise de Dados}

Foram enviados 15 e-mails a pessoas que trabalhavam direta ou indiretamente em empresas de entretenimento. Estas encaminharam a pesquisa a pessoas conhecidas que também atuavam no ramo, totalizando 48 respondentes ao questionário, considerando aqueles que responderam a pesquisa até o fim. Como a pesquisa foi feita no mercado B2B, essa amostra é considerada válida para fins de análise e validação das informações encontradas na pesquisa de dados secundários e no que foi trazido no grupo focal.

Apenas $68,4 \%$ dos prospects deram sequência às questões seguintes, pois confirmaram ser um dos responsáveis pela contratação de fornecedores em sua empresa. Tendo em vista que a empresa a qual este plano de negócio faz menção deverá ser contratada por tais pessoas, elas guiariam as demais respostas.

Metade dos entrevistados nunca utilizou serviços de consultoria nas empresas em que atuam, o que mostra um representativo desconhecimento da prestação desse tipo de serviço por parte das empresas de entretenimento. Isso também indica a necessidade de um trabalho de "aculturamento" de tais empresas para o uso de consultorias. A pesquisa mostrou também que a grande maioria dos entrevistados $(77,1 \%)$ trabalha em empresas que atuam há mais de dez anos no mercado, o que representa maior maturidade em seu ramo de atuação. Isso pode significar que possíveis fornecedores precisam ter credibilidade para atuar junto a empresas que provavelmente serão mais exigentes, por ter mais experiência de mercado.

Dando continuidade à análise dos perfis das empresas avaliadas nessa pesquisa, percebe-se que a grande maioria $(83,3 \%)$ das empresas fatura mais de dois milhões de reais por ano, corroborando com as informações de que o mercado de entretenimento movimenta muito dinheiro.

A Tabela 5 apresenta o perfil dos entrevistados, baseado em duas variáveis: em relação ao setor de atuação das empresas, há destaque para o setor de música, com $20 \%$ dos entrevistados. O item "Outros" é composto por empresas de turismo, produtoras, bares, entre outros. 


\section{Consultoria para a Diversão: Como gerenciar o mercado de entretenimento?}

Tabela 5: Perfil dos entrevistados

\begin{tabular}{l|l|c}
\hline \multicolumn{1}{c|}{ Variável } & \multicolumn{1}{|c}{ Detalhamento } & Frequência \\
\hline & música & $20,8 \%$ \\
Setor de & produtora de cinema & $10,4 \%$ \\
atuação & TV & $10,4 \%$ \\
& teatro & $10,4 \%$ \\
& Outros & $39,6 \%$ \\
\hline & Eu nunca utilizei serviços de consultoria pra & $50,0 \%$ \\
$\begin{array}{l}\text { Uso anterior de } \\
\text { consultoria }\end{array}$ & auxiliar minha empresa. & \\
& Eu já utilizei serviços de consultoria pra auxiliar & $27,1 \%$ \\
& Eu utilizo atualmente serviços de consultoria. & $22,9 \%$ \\
\hline
\end{tabular}

Para que se pudesse entender em que áreas estavam os possíveis contatos para oferecimento do serviço de consultoria, os entrevistados tiveram que especificar em que área da empresa trabalhavam. Diretoria Geral e Marketing representaram $50 \%$ do total, seguido da área de produção, com $25 \%$. Isso permite inferir que não há um caminho único para a venda; isso dependerá do tipo de cliente.

Em relação à percepção dos entrevistados sobre o mercado de entretenimento, abordou-se primeiramente sobre a desorganização do setor. Mas as respostas foram equilibradas e não foi possível definir uma linha de raciocínio (41,7\% discordaram, enquanto $58,3 \%$ concordaram com a afirmação). No entanto, ao cruzar as informações de setor de atuação com essa pergunta, consegue-se afirmar que os setores que se consideram mais desorganizados são os de teatro e eventos. A falta de definição de modelo de negócios e direcionamento estratégico por meio de pesquisas também foi apontada principalmente por esses dois setores, mas no geral, também ficaram equilibradas ( $50 \%$ concordaram que os modelos de negócio não são bem definidos e $58,3 \%$ concordaram que não existe um direcionamento estratégico por meio de pesquisas). No que tange ao amadorismo do setor, também foi necessário fazer um cruzamento de informações que trouxessem respostas que vão além dos 50\% que concordaram com essa informação. Os setores de teatro e cinema ainda se consideram amadores, mesmo com tanto tempo de existência no mercado. Isso pode ser um grande indicativo de que esses setores precisam ser oxigenados com novas ferramentas de negócio que gerem maior maturidade ao setor, possibilitando melhorar essa percepção que as próprias empresas têm a seu respeito. 83,3\% afirma que suas empresas se aproximam do público consumidor, o que significa uma preocupação constante com 0 acompanhamento de suas necessidades. $75 \%$ apontam que gerar conteúdo de qualidade é a maior necessidade do setor.

Quanto às dificuldades encontradas pelo mercado de entretenimento, nota-se que a violência, apesar de ser um fator preocupante nos dias atuais, principalmente na cidade do Rio de Janeiro, não é um grande dificultador dos setores ligados ao entretenimento. Nenhum dos entrevistados concordou totalmente com essa afirmação e $58,3 \%$ discordaram totalmente. No entanto, a maioria dos entrevistados $(58,3 \%)$ acredita que o preço dos 
ingressos pode afetar o crescimento do setor. Isso fica ainda mais evidente em cidades onde existe a lei do meio ingresso a estudantes, sujeito a fraudes e ao aumento do valor do ingresso para os demais espectadores, que acabam deixando de consumir entretenimento por ele ficar muito caro. $16,7 \%$ não concordam, nem discordam e $25 \%$ concordam parcialmente que isso não é uma barreira.

Quando o assunto envolve a participação do governo, fica nítida a paridade da percepção dos entrevistados. Isso porque, apesar do governo investir em cultura, não são todos os setores os beneficiados por ele. Além disso, a falta de critérios mais claros e de uma organização mais voltada à gestão pública do entretenimento, percebida na análise de dados secundários e trazida pelos participantes do grupo focal, faz com que essa percepção fique realmente diferenciada de acordo com o setor.

Com exceção das empresas de TV, os funcionários das demais empresas (58,4\% dos entrevistados) concordam que faltam parceiros de gestão que possam auxiliar o desenvolvimento do setor. Isso permite inferir que há espaço para atuação de especialistas em entretenimento, seja dentro das empresas na forma de consultorias ou como serviços terceirizados que tenham esse conhecimento. No entanto, a percepção das empresas de que não são iniciantes em seu setor de atuação é de 58,4\%.Isso pode trazer alguns empecilhos para empresas que venham a prestar serviços de gestão de negócios a elas, pois se já se consideram maduras no mercado, podem ter certa resistência em aceitar sugestões de terceiros no modo de gerir o negócio em que atuam.

Outra dificuldade é diferenciar os investimentos em cultura dos de entretenimento. Metade das empresas acaba colocando tudo num mesmo pacote, o que faz com que alguns investimentos se percam ou sejam transformados em ferramentas de marketing inadequadas ao que se esperava inicialmente.

Quando o assunto é gestão de negócios, fica evidente a dúvida de alguns setores do entretenimento (33\%), ao mesmo tempo em que mais de $58 \%$ afirma que, se tivesse esse tipo de ajuda, o setor poderia crescer. Com base nesses números, é possível inferir que pode existir espaço pra atuação de consultorias, desde que posicionadas de uma maneira mais amigável, pra não causar desconfiança no setor. Pra finalizar esta etapa de avaliação do mercado de entretenimento, a pesquisa corrobora que há um espaço a ser preenchido por empresas que direcionem estrategicamente os setores de entretenimento. Além dos $25 \%$ que ainda têm dúvida, o baixo percentual $(8,3 \%)$ que discorda dessa afirmação diz respeito ao setor de $\mathrm{TV}$, que se apresenta mais organizado e planejado há mais tempo.

As tabelas a seguir referem-se a perguntas relacionadas à gestão do negócio dos entrevistados, que tiveram como objetivo entender quais eram as necessidades estratégicas dos possíveis clientes da empresa em estudo. Na primeira questão, quase por unanimidade, as informações estratégicas que as empresas mais buscam dizem respeito a estudos de benchmarking e de tendências. Isso comprova a necessidade de direcionamento estratégico que se faz necessário para auxiliar essas empresas. A Tabela 6 mostra também que $70 \%$ buscam informações sobre o crescimento do setor, mostrando uma possivel preocupação com o futuro do seu negócio.

Tabela 6: Informações buscadas pelas empresas de entretenimento

Que tipo de informação você busca a respeito do seu setor de atuação?

atuação das empresas do meu setor no Brasil e no mundo

Tendências

faturamento e movimento do mercado 


\title{
Consultoria para a Diversão: Como gerenciar o mercado de entretenimento?
}

\author{
eventos que estão acontecendo pelo mundo \\ crescimento do setor \\ informações econômicas em geral \\ Concorrência \\ dados em revistas especializadas
}

\author{
$76,9 \%$ \\ $69,2 \%$ \\ $61,5 \%$ \\ $53,8 \%$ \\ $53,8 \%$
}

Já a Tabela 7 apresenta os serviços mais desejados pelas empresas de entretenimento. Os grandes destaques foram pesquisa de mercado (85\%), desenho de projetos (77\%) e treinamento e desenvolvimento de pessoas (54\%). Várias informações podem ser retiradas dos resultados apresentados nesta figura. $O$ fato de a pesquisa ser tão necessária comprova a necessidade de entender mais o consumidor e o mercado onde as empresas atuam. E se ainda não a fazem, é porque podem não se sentir seguras ou acreditar que o preço ainda seja inacessível. Para confirmar tais hipóteses, seria necessária uma nova pesquisa.

Tabela 7: Serviços a serem contratados pelas empresas de entretenimento

\begin{tabular}{l|l}
\hline \multicolumn{2}{c}{$\begin{array}{l}\text { Pensando numa empresa que tivesse foco em prestação de serviços de gestão de negócios em } \\
\text { entretenimento, que serviços você contrataria? }\end{array}$} \\
\hline pesquisa de mercado & $84,6 \%$ \\
desenho de projetos para busca de patrocinadores & $76,9 \%$ \\
treinamento e desenvolvimento de pessoas & $53,8 \%$ \\
desenvolvimento de plano de mídia & $38,5 \%$ \\
desenvolvimento de planos de negócio & $38,5 \%$ \\
campanhas de marketing & $38,5 \%$ \\
planejamento estratégico & $38,5 \%$ \\
reposicionamento de marca & $38,5 \%$ \\
gestão de feiras e eventos & $23,1 \%$ \\
reestruturação organizacional & $23,1 \%$ \\
consultoria financeira & $7,7 \%$
\end{tabular}

O desenho de projetos para a busca de patrocinadores vem ao encontro do que foi mostrado nas tabelas 6 e 7 Por causa da pulverização de investimentos e do aumento da busca das empresas nessa nova arena de comunicação, torna-se fundamental apresentar bons projetos e saber vendê-los adequadamente. Treinamento e desenvolvimento de pessoas aparece como o terceiro serviço mais desejado. O mercado do entretenimento é 
tão específico, que talvez esse possa ser um dos grandes diferenciais da empresa que for atuar com sua gestão.

\section{Considerações Finais}

A análise dos dados permite fazer um quadro geral de oportunidades e ameaças para o mercado de consultoria em entretenimento, como é possível ver no Quadro 1.

Quadro 1: Oportunidades e Ameaças para Consultorias em Entretenimento

\begin{tabular}{|c|c|}
\hline OPORTUNIDADES & AMEAÇAS \\
\hline $\begin{array}{l}\text { - Mercado do entretenimento no Rio de Janeiro ainda } \\
\text { é amador, principalmente o teatro, precisando de } \\
\text { empresas que o direcionem estrategicamente. } \\
\text { - Leis de incentivo do governo para captação de } \\
\text { patrocínios exigem projetos bem estruturados e } \\
\text { objetivos claros. } \\
\text { - Intensa demanda por uma empresa que ofereça } \\
\text { treinamento e desenvolvimento para empresas que } \\
\text { atuem em setores do entretenimento. } \\
\text { - Necessidade de pesquisas de mercado por } \\
\text { empresas que entendam de entretenimento. } \\
\text { - Desenvolvimento de canal de comunicação sobre } \\
\text { benchmarkings e tendências nacionais e } \\
\text { internacionais de alguns setores do entretenimento. }\end{array}$ & $\begin{array}{l}\text { - Profissionais que atuam no mercado de } \\
\text { entretenimento são fechados e desconfiados. } \\
\text { - Cultura do mercado de entretenimento no Rio de } \\
\text { Janeiro ser feita principalmente por meio de lobby, } \\
\text { dificultando um acesso inicial a possíveis clientes. } \\
\text { - A empresa pode ser confundida como mais uma } \\
\text { produtora de eventos e não como uma empresa que } \\
\text { atua na gestão do negócio. } \\
\text { - Participação maciça de novas empresas que } \\
\text { atuam e se posicionam como "gestão", mas que na } \\
\text { verdade atuam operacionalmente. }\end{array}$ \\
\hline
\end{tabular}

Todo esse cenário pode causar uma mudança na demanda por shows musicais, que precisarão se adaptar a essas novas mídias para garantir continuidade das receitas. Pensar em novas formas de show, de como atrair 0 público, se tornará um grande diferencial para este setor. Já no setor de eventos esportivos, além da Copa do Mundo de 2014, o Rio de Janeiro também sediará as Olimpíadas de 2016. Isso confirma a necessidade de empresas especializadas em gestão de entretenimento que possam auxiliar a concretizar todos esses eventos. E no teatro, a demanda vai de encontro ao que foi passado por alguns diretores de teatro e pelos responsáveis por teatros como o Oi Casa Grande, afirmando que o setor entrou numa etapa em que precisa se profissionalizar. Profissionais de marketing estão sendo contratados pra dar um ar mais profissional ao setor. 0 Rio de Janeiro tem foco no humor e um comportamento de consumo bem peculiar. $O$ entendimento desse comportamento também pode facilitar o trabalho dos grandes teatros e espetáculos. Existem cerca de 70 teatros na cidade e o volume de possíveis clientes poderá ser intenso se um grande projeto for feito com algum deles.

Essas análises permitem concluir que uma empresa de gestão de negócios em entretenimento é viável e que teria chances de obter sucesso, se souber lidar com as ameaças apontadas. É necessário também direcionar as atividades e os clientes iniciais, a fim de consolidar a imagem da organização e criar uma rede de referências que possa ser o grande cartão de visita da empresa. Isso porque, para se posicionar bem em um mercado repleto de "estrelas", é necessário passar credibilidade e profissionalismo.

Também ficou claro neste estudo que, independentemente do foco inicial que seja dado ou do serviço a ser oferecido, é preciso posicionar-se muito bem pra não gerar dúvida nos profissionais deste mercado. Isso por 


\section{Consultoria para a Diversão: Como gerenciar o mercado de entretenimento?}

dois motivos principais: pra não ser confundido com as produtoras e pra diferenciar-se num mercado que espera por uma empresa desse tipo (que disponibilizará métodos e ferramentas de gestão com expertise de entretenimento), mas que pode não saber identificá-la tão facilmente num primeiro momento.

No que se refere aos serviços a serem prestados, fica clara a necessidade por pesquisas, desenhos de projetos e preparação de material para treinamento e desenvolvimento de pessoas. Ao mesmo tempo, numa comparação conjunta com outros dados levantados na pesquisa, essas empresas buscam constantemente informações sobre tendências e benchmarkings nacionais e internacionais em seus setores de atuação, principalmente por meio de sites e revistas especializadas no tema. Pode haver aí outra forma de se pensar estrategicamente em como se aproximar dessas empresas.

Considerados no contexto de um universo de possibilidades do mercado, os principais prognósticos para uma empresa que atue em consultoria para entretenimento são:

a) atuação no mercado de entretenimento como um todo, focando nos três setores citados anteriormente: shows musicais, eventos esportivos e teatro. Isso não impede que a empresa atue nos demais setores, quando demandada. Esse foco será o grande diferencial para solidificar o posicionamento da empresa.

b) a prestação de serviços deve ser focada inicialmente em pesquisas, desenhos de projetos e desenho de treinamento e desenvolvimento de pessoas. Isso também deve fazer parte do posicionamento da empresa.

c) os clientes devem prioritariamente estar no Rio de Janeiro e podem estar em qualquer etapa do seu ciclo de vida (início, crescimento ou maturidade).

\section{NOTAS}

1. "P2P (do inglês peer-to-peer, que significa par-a-par) é um formato de rede de computadores em que a principal característica é descentralização das funções convencionais de rede, onde o computador de cada usuário conectado acaba por realizar funções de servidor e de cliente ao mesmo tempo. Seu principal objetivo é a transmissão de arquivos e seu surgimento possibilitou o compartilhamento em massa de músicas e filmes. Com a crescente utilização da rede P2P para este fim, cada vez mais surgem programas para este fim, porém nem sempre eles atendem às expectativas do usuário." (Douglas Siriaco, 2008)

2. Negócio que se baseia no esforço coletivo de um grupo de pessoas ou organizações e pode atuar em diferentes mercados e atividades. No caso do crowd funding "Queremos", os fãs mobilizam-se para trazer determinado artista comprando o ingresso antes de saberem se o show vai acontecer com o objetivo de financiá-lo. Se conseguirem arrecadar o valor necessário para a realização do evento, já têm seus ingressos garantidos, caso não, recebem seu dinheiro de volta. Nesse caso, o cliente tem participação ativa na produção do show.

\section{Referências}

ANDERSON, Chris. A Cauda Longa: do mercado de massa para o mercado de nicho. São Paulo: Campus, 2007.

CANAN, Felipe; CALEGARI,Décio Roberto. Fatores determinantes para a relação ofertal demanda do campo esportivo. Santa Catarina: UFSC, 2006.

CULTURA E MERCADO. Shows no Brasil já representam $\mathbf{R} \$ \mathbf{5 7}$ milhões em direitos autorais. Disponível em < http://www.culturaemercado.com.br/mercado/shows-no-brasil-ja-representam-r-57-milhoes-em-direitosautorais >. Acesso em 28 de setembro de 2012. 
DELOITTE. A nova natureza dos negócios: Os complexos caminhos que liga a empresa aos seus públicos. 0 Mundo Corporativo, $\mathrm{n}^{0}$ 24, abril-junho de 2009. Disponível em <http://www.deloitte.com/assets/DcomBrazi/Local\%20Assets/Documents/Mundo\%20Corporativo\%2024.pdf>. Acesso em 07 de setembro de 2012.

ESPORTES. Disponível em <http://www.esporte.gov.br> Acesso em 28 setembro de 2012.

FAGUNTES, Letícia. Visão e tendência: Cirque du Soleil. Boletim Mercado, SEBRAE, Ed. 35, Ano VI, setembro de 2012.

Disponível

em

<http://sv.www5.fgv.br/fgvonline/universidadecorporativasebrae/boletins/2010/boletim\%20_de_mercado_n\%C2\% BA\%2035\%20ano\%20vi.pdf>. Acesso em 07 de setembro de 2012.

HERSCHMANN, Micael; ALBOMOZ, Luís A..Transformações recentes da indústria da música. Disponível em <http://www.cult.ufba.br/enecult2009/19056.pdf>. Acesso em 28 de setembro de 2012.

INSTITUTO IPSOS MARPLAN. O Dossiê Esporte: Um estudo sobre o esporte na vida do brasileiro. Sportv. 2006. Disponível em

<http://globosat.globo.com/sportv/hotsite/dossie/dossie_esporte.swf>. Acesso em 29 de setembro de 2008.

KOTLER, Philip. Administração de marketing: análise, planejamento, implementação e controle. São Paulo: Atlas, 1998.

LEI 11.438 DE 29 DE DEZEMBRO DE 2006. Disponível em <http://www.planalto.gov.br/ccivil_03/_ato20042006/2006/lei//11438.htm>. Acesso em 28 de setembro de 2012.

MALHOTRA, Naresh K. Pesquisa de marketing: uma orientação aplicada. Tradução de

Nivaldo Montingelli Jr. e Alfredo Alves de Farias. Porto Alegre: Bookman, 2001.

MARIN.Elizara Caroline. 0 espetáculo esportivo no contexto da mundialização do entretenimento midiático. Revista Brasileira Ciência Esporte. Campinas, v.30, n.1, p.75 -89, set.2008.

MELODY BOX. A reinvenção do mercado. Disponível em <http://www.melodybox.com.br/blog/index.php/areinvencao-do-mercado/>. Acesso em 28 de setembro de 2012.

NETO, Manoel Marcondes Marchado. Marketing Cultural: das práticas à teoria. Rio de Janeiro: Ciência Moderna, 2005.

O GLOBO. Rio tem os ingressos mais caros do mundo. Disponível em <http://oglobo.globo.com/cultura/riotem-os-ingressos-mais-caros-do-mundo-4526331>. Acesso em 29 de outubro de 2012.

PLURI CONSULTORIA. 0 PIB do Esporte Brasileiro. Disponível em: $\langle$ http://www.pluriconsultoria.com.br/uploads/relatorios/PIB\%20Esporte.pdf $>$. Acesso em 29 de setembro de 2012.

PORTER, Michael E. Estratégia Competitiva. Rio Janeiro: Campus, 1991.

PORTER, Michael E. How competitive forces shape strategy. Harvard Business Review, Nov./Dec., 1979.

PRICEWATERHOUSECOOPERS. Global Entertainment and Media Outlook 2011-2015. 12ed. Disponível em <http://boletines.prisadigital.com/PwCOutlook2011-Industry\%20overview.pdf>. Acesso em 28 setembro de 2012.

SIQUEIRA, Chris. 0 príncipe das falcatruas. Revista Super Interessante, São Paulo: Ed.198. Disponível em <http://super.abril.com.br/superarquivo/2004/conteudo_320212.shtml>. Acesso em 28 setembro de 2012.

TECMUNDO. 0 que é P2P. Disponível em <http://www.tecmundo.com.br/torrent/192-0-que-e-p2phtm\#ixzz2BOwawOLB>. Acesso em 01 novembro de 2012. 